OPEN ACCESS

Edited by:

Xiancang Ma,

First Affiliated Hospital of Xi'an Jiaotong University, China

Reviewed by:

Kenji Hashimoto,

Chiba University, Japan

Gang Zhu,

China Medical University, China Bin Zhang,

Southern Medical University, China

${ }^{*}$ Correspondence: Shengxi Wu shengxi@fmmu.edu.cn Fang Kuang

kuangf@fmmu.edu.cn

${ }^{\dagger}$ These authors have contributed equally to this work

Specialty section: This article was submitted to Mood and Anxiety Disorders, a section of the journal

Frontiers in Psychiatry

Received: 21 May 2020 Accepted: 29 June 2020

Published: 10 July 2020

Citation:

Liu Z, Yin R, Fan Z, Fan H, Wu H, Shen B, Wu S and Kuang F (2020) Gender Differences in Associated and

Predictive Factors of Anxiety and Depression in People With Epilepsy.

Front. Psychiatry 11:670.

doi: 10.3389/fpsyt.2020.00670

\section{Gender Differences in Associated and Predictive Factors of Anxiety and Depression in People With Epilepsy}

\author{
Zhao Liu ${ }^{1,2 \dagger}$, Rong Yin ${ }^{2 \dagger}$, Ze Fan ${ }^{1,3}$, Hong Fan ${ }^{1}$, Haiyan $W^{2}$, Baorui Shen ${ }^{1}$, Shengxi $W^{1 *}$ \\ and Fang Kuang ${ }^{1 *}$
}

1 Department of Neurobiology, School of Basic Medicine, Fourth Military Medical University, Xi'an, China, ${ }^{2}$ Department of
Neurology, The 940th Hospital of Joint Logistics Support Force of People's Liberation Army, Lanzhou, China, ${ }^{3}$ Department of Anesthesiology, Xijing Hospital, Fourth Military Medical University, Xi'an, China

Purpose: Comorbid anxiety and depression in people with epilepsy (PWE) are highly prevalent and contribute to low quality of life (QOL) and may even lead to poor outcomes of epilepsy. Among the various factors that affect these negative emotional comorbidities, possible gender differences remain poorly understood and are often neglected. This research aimed to determine whether there are discrepancies in the incidence and influence factors of anxiety and depression between men and women with epilepsy in a hospital in northwest China.

Methods: A total of 158 adult PWE (female: $N=65 ; 41.1 \%$ ) completed self-report questionnaires, including the Self-rating Anxiety Scale (SAS), the Self-rating Depression Scale (SDS), the Chinese version of the Quality of Life in Epilepsy-31 (QOLIE-31) inventory and the Pittsburgh Sleep Quality Inventory (PSQI). The comparison between male and female PWE was made by regression analysis.

Results: For the prevalence of anxiety and depression in PWE, no gender difference was found in this study. However, the moderating factors of psychiatric comorbidities were significantly different between men and women: male PWE with comorbid anxiety were more likely to be affected by sleep quality, while anxiety symptoms in female PWE were closely associated with the frequency of seizures. Education years and QOL social function were significant indicators of depression in male PWE but not in female PWE. The important and common predictor for anxiety and depressive symptoms in PWE was QOL energy/fatigue, with male patients being more affected.

Conclusion: For the PWE included in this study, the incidence of comorbid anxiety and depression in PWE was similar for men and women, but the moderating factors affecting comorbid anxiety and depressive disorders differed between genders: male PWE were more likely to be affected by psychosocial factors, while female PWE were more influenced by epilepsy itself. This exploration suggests that gender-specific health care should be considered in epilepsy therapy to improve the psychiatric condition and QOL of PWE, and different treatments should be conducted for male and female PWE to prevent negative emotional comorbidities.

Keywords: epilepsy, anxiety, depression, psychiatric comorbidity, gender differences, risk factors 


\section{INTRODUCTION}

Anxiety and depression as high-rate psychiatric comorbidities are more common in people with epilepsy (PWE) (prevalence: 20\%$50 \%)$ than in the general population (prevalence: 7\%-20\%) (1-5)]. The relationship between epilepsy and psychiatric disturbance is bidirectional; specifically, PWE are more prone to develop psychiatric comorbidities, while patients with certain primary psychiatric disorders are at higher risk of developing epilepsy (6). This bidirectional relation may be explained by the common pathogenesis of both epilepsy and psychiatric disorders (7). Psychiatric comorbidities, especially depression and anxiety, impact seizure disorders and the lives of PWE. To improve quality of life and promote efficiency in the treatment of epilepsy, screening for anxiety and depression and seeking for possible causes should become a necessary clinical routine. Unfortunately, psychiatric comorbidities often go unrecognized and untreated in PWE (8).

Although studies have found that women usually experience higher levels of anxiety and depression than men in the general population $(9,10)$, little is known about the gender differences in comorbid psychological disorders in epilepsy. So far, only one study has estimated the gender differences in the incidence of comorbid anxiety and depression in PWE and found that female patients with epilepsy are more susceptible to be affected by depression than male patients, but there is no gender difference in the prevalence of anxiety [(10). Therefore, more evidence is needed to increase the understandings of the gender differences in comorbid anxiety and depression in PWE.

Based on the gender discrepancy in psychiatric disorders, we hypothesized that there should be differences between male and female PWE in comorbid anxiety and depression. So the objective of the present study was to seek out gender differences in sociodemographic, clinical, incidence and risk factors of epilepsy comorbid anxiety/depression symptoms by investigating adult PWE in our hospital located in northwest China. Using statistical analyses of data obtained by selfrating questionnaires, we found differences between genders in the most predictors but not prevalence of epilepsy comorbid negative emotions.

\section{SUBJECTS AND METHODS}

\section{Participants and Recruitment}

All 158 (male 93, female 65) adult PWE were recruited from the outpatient and inpatient Department of Clinical Neurology, the 940th Hospital of Joint Logistics Support Force of People's Liberation Army (Lanzhou, Gansu Province, China). Patients were consecutively enrolled in this study between March 2017 and November 2017. The included patients should meet following criteria: (1) older than 18 years, (2) no other systemic disease, and (3) epilepsy was diagnosed by experienced epileptologists according to the International League against Epilepsy, (4) cognitively capable of communicating with physicians and understanding the questionnaires. After recruited the patients, resident doctors sent the questionnaires to the patients and helped them to fill in; physicians, attending doctors were responsible for collecting and analyzing data.

This study was approved by the Institutional Review Board prior to initiation, and each participant was consent and signed the patient's medical notes to collect demographic and clinical information, including age, gender, years of education, occupational status, age at onset, duration of seizures, the number of antiepileptic drugs (AEDs) used daily, frequency of AED use, selfreported adverse effects of AEDs and frequency of seizures.

\section{Assessment Scales \\ Self-Rating Anxiety Scale and Self-Rating Depression Scale}

We adopted the Self-rating Anxiety Scale (SAS) and the Selfrating Depression Scale (SDS) to assess anxiety and depression in the enrolled PWE. The SAS and SDS are widely used questionnaires among PWE, and their Chinese versions were administered in a previous study $(11,12)$. Either the SAS or the SDS composes 20 -item symptom inventories, and each item is rated on a scale from 1 to 4 . The total score is multiplied by 1.25 and is then converted into a standardized score ranging from 25 to 100 , with higher scores reflecting more severe anxiety and depression. The criteria of severities applied in China are as the following: mild anxiety (score 50-60) and mild depression (score 53-62), moderate anxiety (score 61-70) and moderate depression (score 63-72), and severe anxiety (score $>70$ ) and severe depression (score $>72$ ) (13).

\section{Quality of Life in Epilepsy-31 Inventory}

Quality of life was assessed using the Chinese version of the Quality of Life in Epilepsy-31 (QOLIE-31) inventory, which is widely acknowledged epilepsy-specific QOL instruments and shows good validity and reliability in Chinese populations (1416). The QOLIE-31 contains seven multi-item scales: seizure worry, overall quality of life (QOL), emotional well-being, energy/fatigue, cognitive function, medication effects and social function. The QOLIE-31 overall score is the sum of the weighted average of each subscale score, ranging from 1 to 100, with higher scores meaning a more favorable QOL $(17,18)$.

\section{Pittsburgh Sleep Quality Inventory}

The Pittsburgh Sleep Quality Inventory (PSQI) is a self-report questionnaire for assessing sleep. The global score ranges from 0 to 21 , with a higher score indicating poorer sleep quality. The scale consists of seven subscales, comprising subjective sleep quality, sleep latency, sleep duration, sleep efficiency, sleep disturbance, use of sleep medications and daytime dysfunction. A total PSQI score of 5 or more points indicates poor sleep quality, and more than 10 points is considered severely disturbed sleep (19).

\section{Statistical Analysis}

All data were analyzed using the software package SPSS 23.0. Descriptive statistics were calculated for all variables. Quantitative data are expressed as the mean \pm standard deviation (SD). Qualitative data are shown and summarized as numbers and proportions. 
Gender differences were compared using Student's t-test for continuous variables and Chi-square tests for categorical variables. To explore the relationships between depression/anxiety and sociodemographic, psychosocial and clinical variables, Pearson's $r$ was calculated. The independent variables correlating with anxiety or depression, which were defined as the scores of SAS $(\geq 50)$ and SDS ( $\geq 53$ ), respectively, were introduced into a logistic regression model with stepwise selection. All tests for statistical significance were two-sided, and $p<0.05$ was considered significant.

\section{RESULTS}

\section{Demographic and Clinical Characteristics}

The demographic and clinical characteristics of 158 PWE (93 male and 65 female) are summarized in Table $\mathbf{1}$ and Figures 1 and 2. Most parameters were similar in male and female patients. The significant difference between genders was only found in terms of education years in which male patients had a longer education time than female patients (Figure 1C).

\section{Prevalence of Anxiety and Depressive Symptoms}

The SAS and SDS scores for all participants are listed in Table 2 and Figures 3A, B. Of the 158 patients, the mean overall scores of the SAS and SDS were $45.28(\mathrm{SD}=12.29)$ and $49.28(\mathrm{SD}=13.20)$, respectively. No significant difference was found between genders in the percentage of subjects with high SAS and SDS scores.

\section{Other Inventory Results}

The overall and subscale scores of the QOLIE-31 and PSQI are shown in Table 3 and Figure 3. For the overall sample, the mean overall QOLIE-31 score was $62.29(\mathrm{SD}=16.30)$. According to the PSQI rating scale, only $28.5 \%$ of the total PWE participated declared good quality of sleep, but $51.3 \%$ had poor sleep, and $20.3 \%$ reported severely disturbed sleep, respectively (Figure 3C). The female PWE had higher Sleep Quality score than the male $(p=0.023)$, and no significant gender difference was found in terms of any other total or subscale scores of the PSQI and QOLIE-31 (Figures 3D-K).

\section{Correlation Analysis}

\section{Gender Differences in the Correlation Between Clinical Variables and Anxiety (SAS Scores)}

Table 4 outlines a univariate correlation analysis between various factors and SAS scores in men and women with epilepsy. The correlation analysis revealed that anxiety (SAS scores $\geq 50$ ) in both men and women with epilepsy was positively correlated with the frequency of seizures (men: $\mathrm{r}=0.207, p<$ 0.05; women: $\mathrm{r}=0.467, p<0.05$ ), the overall QOLIE-31 scores (men: $\mathrm{r}=-0.522, p<0.01$; women: $\mathrm{r}=-0.606, p<0.01$ ) and the PSQI scores (men: $\mathrm{r}=0.467, p<0.01$; women: $\mathrm{r}=0.445, p<$ 0.01 ). In addition, anxiety in women with epilepsy was positively correlated with occupation $(\mathrm{r}=-0.394, p<0.01)$, years of
TABLE 1 | Gender differences in demographic and clinical characteristics.

\begin{tabular}{|c|c|c|c|c|}
\hline Characteristics & $\begin{array}{l}\text { Total sample } \\
\qquad(\mathrm{N}=158)\end{array}$ & $\begin{array}{c}\text { Men } \\
(\mathrm{N}=93)\end{array}$ & $\begin{array}{l}\text { Women } \\
(\mathrm{N}=65)\end{array}$ & $p$ \\
\hline \multicolumn{5}{|l|}{ Gender, n (\%) } \\
\hline Male & 93 (58.9) & $93(100)$ & - & \\
\hline Female & $65(41.1)$ & - & 65(100) & \\
\hline $\begin{array}{l}\text { Age, years } \\
(\text { mean } \pm \mathrm{SD})\end{array}$ & $26.39 \pm 10.10$ & $26.02 \pm 9.11$ & $26.92 \pm 11.44$ & 0.583 \\
\hline Settlement, n (\%) & & & & 0.064 \\
\hline Rural area & $76(48.1)$ & 39 (41.9) & $37(56.9)$ & \\
\hline Urban area & $82(51.9)$ & $54(58.1)$ & $28(43.1)$ & \\
\hline $\begin{array}{l}\text { Education years } \\
(\text { mean } \pm \mathrm{SD})\end{array}$ & $10.27 \pm 3.86$ & $10.80 \pm 3.35$ & $9.52 \pm 4.42$ & 0.041 \\
\hline $\begin{array}{l}\text { Occupation status, } \\
\text { n (\%) }\end{array}$ & & & & 0.098 \\
\hline Full-time student & $38(24.1)$ & $20(21.5)$ & $18(27.7)$ & \\
\hline Employed & $67(42.4)$ & $46(49.5)$ & $21(32.3)$ & \\
\hline Unemployed & 53 (33.5) & $27(29.0)$ & $26(40.0)$ & \\
\hline $\begin{array}{l}\text { Age of onset, years } \\
\text { (mean } \pm \mathrm{SD} \text { ) }\end{array}$ & $20.33 \pm 3.86$ & $20.28 \pm 11.47$ & $20.41 \pm 12.22$ & 0.946 \\
\hline $\begin{array}{l}\text { Duration of seizures, } \\
\text { years (mean } \pm S D \text { ) }\end{array}$ & $5.98 \pm 7.00$ & $6.07 \pm 7.59$ & $5.83 \pm 6.08$ & 0.833 \\
\hline $\begin{array}{l}\text { Number of AEDs used } \\
\text { daily, } n(\%)\end{array}$ & & & & 0.082 \\
\hline 0 & $66(41.8)$ & $43(46.2)$ & $23(35.4)$ & \\
\hline 1 & $57(36.1)$ & $28(30.1)$ & $29(44.6)$ & \\
\hline 2 & $23(14.6)$ & $12(12.9)$ & $11(16.9)$ & \\
\hline$\geq 3$ & $12(7.6)$ & $10(10.8)$ & $2(3.1)$ & \\
\hline $\begin{array}{l}\text { Frequency of seizures, } \\
n(\%)\end{array}$ & & & & 0.319 \\
\hline Seizrue free $>1$ year & $50(31.7)$ & $29(31.2)$ & 21 (32.3) & \\
\hline$\geq 1$ per 1 year & $15(9.5)$ & $7(7.5)$ & $8(12.3)$ & \\
\hline$\geq 1$ per 6 months & $27(17.1)$ & $13(14.0)$ & $14(21.5)$ & \\
\hline$\geq 1$ per 3 months & $23(14.6)$ & $15(16.1)$ & $8(12.3)$ & \\
\hline monthly & $19(12.0)$ & $15(16.1)$ & $4(6.2)$ & \\
\hline weekly & $18(11.4)$ & $11(11.8)$ & 7 (10.8) & \\
\hline daily & $6(3.8)$ & 3 (3.2) & $3(4.6)$ & \\
\hline Type of epilepsy, n (\%) & & & & 0.662 \\
\hline Generalized epilepsy & $138(87.3)$ & $82(88.2)$ & $56(86.2)$ & \\
\hline Partial epilepsy & $17(10.8)$ & $10(10.8)$ & 7 (10.8) & \\
\hline Unclassified epilepsy & $3(1.9)$ & $1(1.1)$ & $2(3.1)$ & \\
\hline
\end{tabular}

AEDs, antiepileptic drugs; SD, standard deviation.

education ( $\mathrm{r}=-0.422, p<0.01)$ and settlement $(\mathrm{r}=-0.330$, $p<0.01)$. There were also significant differences in the correlations between anxiety and each subscale domain of the QOLIE-31 and PSQI, which are listed in Table 4.

\section{Gender Differences in the Correlation Between Clinical Variables and Depression (SDS Score)}

The correlational analysis showed that depression in men with epilepsy was positively correlated with education years $(\mathrm{r}=-0.279$, $p<0.01)$, frequency of seizures $(\mathrm{r}=0.321, p<0.01)$, QOLIE-31 scores $(\mathrm{r}=-0.615, p<0.01)$ and PSQI scores $(\mathrm{r}=-0.501, p<0.01)$. In contrast, depression in women with epilepsy was positively correlated with occupation $(\mathrm{r}=-0.394, p<0.01)$, years of education ( $\mathrm{r}=-0.422, p<0.01)$, settlement $(\mathrm{r}=-0.330, p<$ $0.01)$, QOLIE-31 scores $(\mathrm{r}=-0.615, p<0.01)$ and PSQI scores $(\mathrm{r}=-0.501, p<0.01)$. 


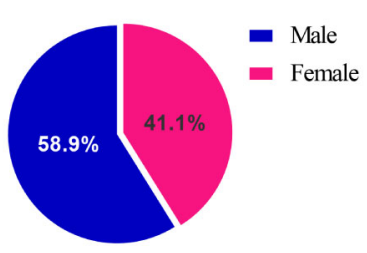

Total $=\mathbf{1 5 8}$
B

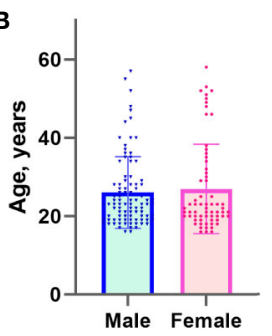

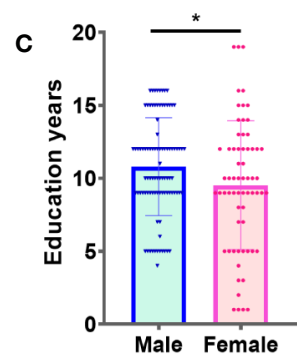

D

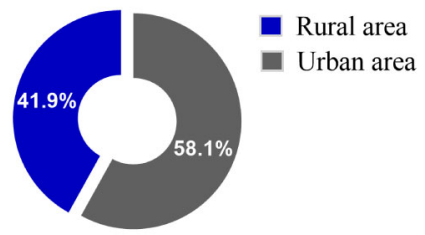

Male $=93$

\section{Settlements}

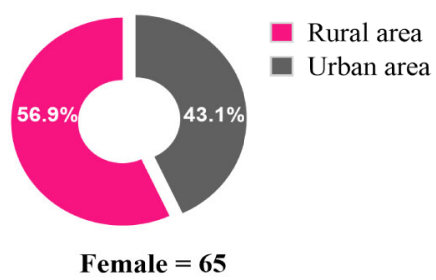

Female $=65$

\section{E}
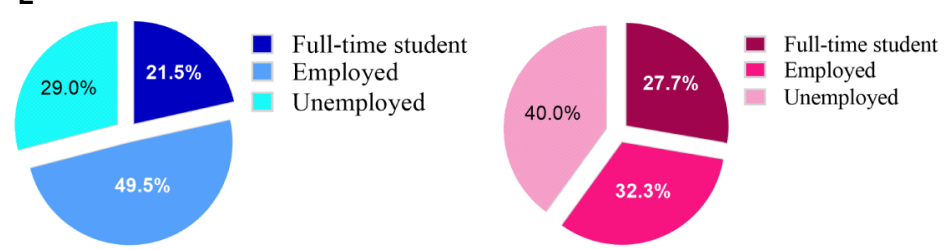

Male $=93$

\section{Occupation status}

FIGURE 1 | Demographic characteristics of male and female patients with epilepsy included in this study. The number of cases (A), ages (B), education years (C), settlements (D) and occupation status (E) of male and female patients were indicated, respectively.

\section{Logistic Regression Analysis}

\section{Gender Differences in Predictors of Anxiety}

Logistic regression models for the male group explained the independent predictors of the SAS score. These predictors included energy/fatigue $(\mathrm{OR}=0.432)$ as the subscale of the QOLIE-31 and the PSQI score $(\mathrm{OR}=1.339)$ (Table 5). In the female group, energy/fatigue $(\mathrm{OR}=0.151)$ and frequency of seizures $(\mathrm{OR}=3.001)$ significantly predicted the SAS score (Table 5).

\section{Gender Differences in Predictors of Depression}

Logistic regression analysis indicated that education years $(\mathrm{OR}=$ $0.769)$, energy/fatigue $(\mathrm{OR}=0.482)$ and social function $(\mathrm{OR}=$ 0.698), as the subscales of the QOLIE-31, independently predicted depression for the male group (Table 6). In the female group, only energy/fatigue $(\mathrm{OR}=0.265)$ was a significant indicator of depression (Table 6).

\section{DISCUSSION}

Gender discrepancy usually exists in psychiatric disorders. However, that difference(s) between genders may not always be the same in all kinds of scenarios. The current study investigated gender differences in the demographic variables, incidence and risk factors of comorbid anxiety and depression in PWE and have three key findings in the present study: (1) Expected gender differences in the prevalence of anxiety and depression are not actually seen in PWE. (2) Most of the important predictors for anxiety and depression in PWE vary by gender. (3) QOL energy/fatigue is the common influential factor of anxiety and depression in PWE and influences male and female PWE to different extents.

Large-scale epidemiological studies suggest that anxiety disorders are much more prevalent in women than in men, and this gender disparity is even more pronounced in other neuropsychiatric disorders, such as sleep disturbance (20). However, this study revealed no gender difference in the high prevalence rates of comorbid anxiety in PWE, which was consistent with previous studies $(21,22)$. Women in general are also documented to be more prone to depression than men $(9,10,23)$, and recent evidence (22) also showed the female PWE had a higher ratio of comorbid depressive symptoms than the male. Paradoxically, the present study showed that men with epilepsy were just as likely as female patients to exhibit markedly 
A

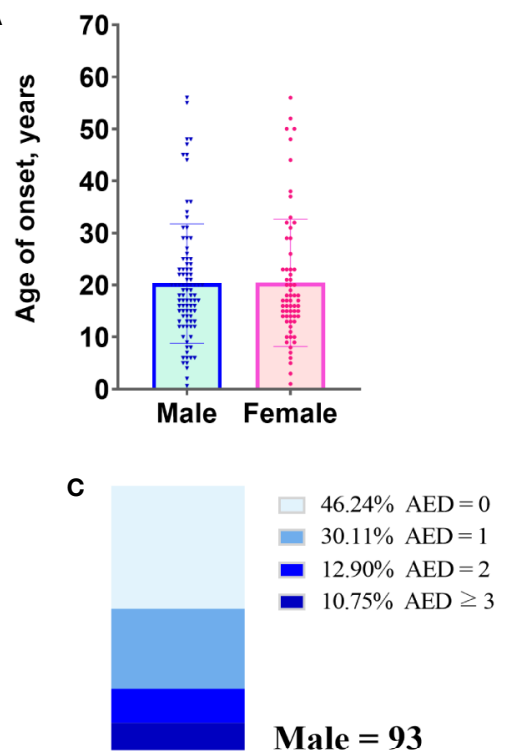

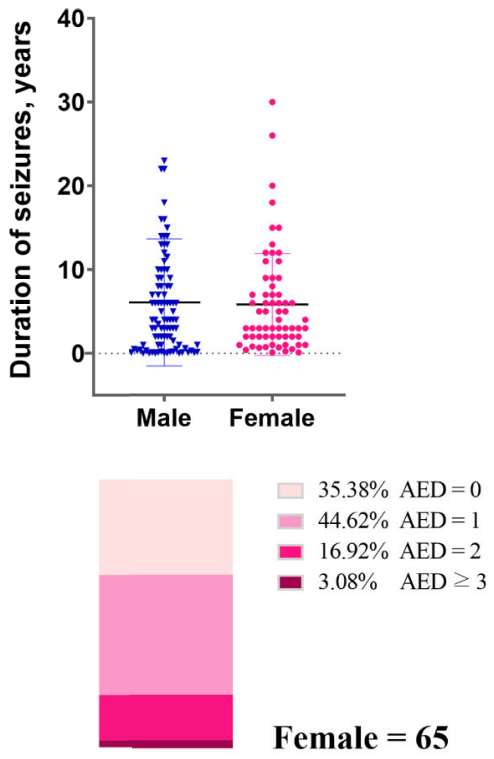

Number of AEDs used daily

D

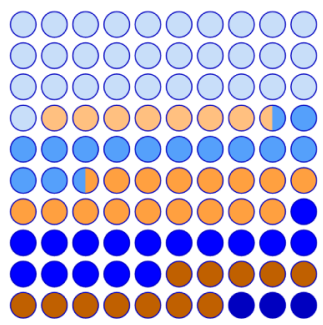

$\square$ Seizrue free $>1$ year

$\geq 1$ per 1 year

$\geq 1$ per 6 months

$\geq 1$ per 3 months

monthly

weekly

daily

Male $=93$

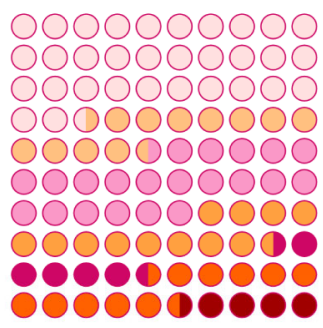

Seizrue free $>1$ year

$\geq 1$ per 1 year

$\geq 1$ per 6 months

$\geq 1$ per 3 months

monthly

weekly

daily

Female $=65$

Frequency of seizures

FIGURE 2 | Clinical characteristics of male and female patients included in this study. (A) Age of onset years. (B) Duration of seizures. (C) Number of antiepileptic drugs (AEDs) used daily. (D) Frequency of seizures.

higher levels of depression in comparison to the general population. Such discrepancies may be attributed to the different features of the selected samples among these studies. Significantly, the patients in this study were mainly from Gansu, a province of northwest China where economy and healthcare conditions are relatively under-developed. The unemployed and poorly educated situations may greatly impact the emotions of those participants. Nevertheless, our findings indicate that psychiatric comorbidities in male PWE must be concerned as important as in female patients, and the psychological state of PWE should not be equated with that of the general population.
Although the expected gender difference in the prevalence of anxiety and depression in PWE was not observed in this study, the important predictors of comorbid anxiety were found in this study quite complex and differed between male and female PWE. In men with epilepsy, poor sleep is the most dangerous factor in comorbid anxiety disorders. Sleep problems occur more frequently in PWE than in healthy controls (24). Sleep disturbance is a well-documented risk factor for developing or worsening anxiety disorders $(25,26)$, and women in the general population are more likely than men to report insomnia (25-27). Surprisingly, this study showed that men and women with 
TABLE 2 | Mood self-evaluation inventory scores.

\begin{tabular}{|c|c|c|c|c|}
\hline Items & Total sample( $\mathbf{N}=158)$ & $\operatorname{Men}(\mathbf{N}=93)$ & Women $(\mathrm{N}=65)$ & $p$ \\
\hline \multicolumn{5}{|l|}{ Anxiety and depression } \\
\hline SAS (mean \pm SD) & $45.28 \pm 12.29$ & $45.56 \pm 12.59$ & $44.88 \pm 11.92$ & 0.732 \\
\hline Normal, n (\%) & $108(68.4)$ & $61(65.6)$ & $47(72.3)$ & 0.671 \\
\hline Mild & $28(17.7)$ & $19(20.4)$ & $9(13.8)$ & \\
\hline Moderate & $13(8.2)$ & $7(7.5)$ & $6(9.2)$ & \\
\hline Severe & $9(5.7)$ & $6(6.5)$ & $3(4.6)$ & \\
\hline SDS (mean \pm SD) & $49.28 \pm 13.20$ & $48.75 \pm 13.62$ & $50.03 \pm 12.65$ & 0.551 \\
\hline Normal, n (\%) & $100(63.3)$ & $57(51.6)$ & $43(66.2)$ & 0.773 \\
\hline Mild & $31(19.6)$ & $20(21.5)$ & $11(16.9)$ & \\
\hline Moderate & $17(10.8)$ & $11(20.4)$ & $6(9.2)$ & \\
\hline Severe & $10(6.3)$ & $5(6.5)$ & $5(7.7)$ & \\
\hline
\end{tabular}

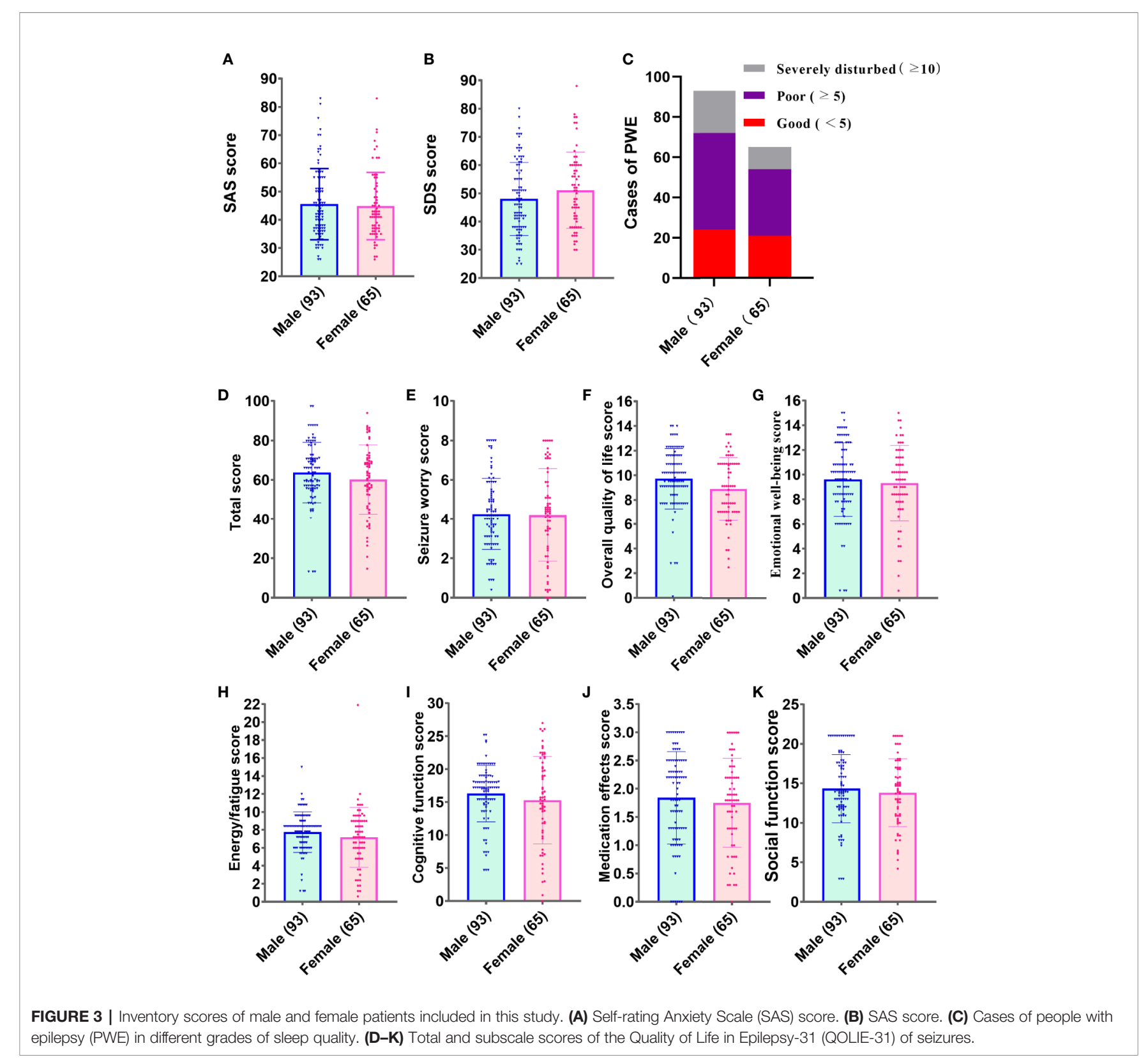


TABLE 3 | Other inventory scores.

\begin{tabular}{|c|c|c|c|c|}
\hline Items & $\begin{array}{l}\text { Total sample } \\
\qquad(\mathrm{N}=158)\end{array}$ & $\begin{array}{c}\text { Men } \\
(N=93)\end{array}$ & $\begin{array}{l}\text { Women } \\
(\mathrm{N}=65)\end{array}$ & $p$ \\
\hline \multicolumn{5}{|l|}{ QOLIE-31 } \\
\hline $\begin{array}{l}\text { Total } \\
\text { score }(\text { mean } \pm \mathrm{SD})\end{array}$ & $62.29 \pm 16.30$ & $61.48 \pm 17.03$ & $63.45 \pm 15.25$ & 0.467 \\
\hline Seizure worry & $4.24 \pm 2.05$ & $4.42 \pm 2.13$ & $4.28 \pm 1.95$ & 0.848 \\
\hline Overall quality of life & $9.37 \pm 2.52$ & $9.11 \pm 2.75$ & $9.74 \pm 2.11$ & 0.124 \\
\hline Emotional well-being & $9.48 \pm 3.00$ & $9.52 \pm 3.12$ & $9.42 \pm 2.86$ & 0.841 \\
\hline Energy/fatigue & $7.51 \pm 2.76$ & $7.36 \pm 2.65$ & $7.72 \pm 2.91$ & 0.421 \\
\hline Cognitive function & $15.88 \pm 5.38$ & $15.84 \pm 5.69$ & $15.95 \pm 4.93$ & 0.896 \\
\hline Medication effects & $1.81 \pm 0.81$ & $1.84 \pm 0.80$ & $1.75 \pm 0.81$ & 0.493 \\
\hline Social function & $14.12 \pm 4.30$ & $13.76 \pm 4.52$ & $14.62 \pm 3.96$ & 0.217 \\
\hline \multicolumn{5}{|l|}{ PSQI, n (\%) } \\
\hline Good $(<5)$ & $45(28.5)$ & $24(25.8)$ & 21 (32.3) & 0.555 \\
\hline Poor $(\geq 5)$ & $81(51.3)$ & $48(51.6)$ & $33(50.8)$ & \\
\hline $\begin{array}{l}\text { Severely disturbed } \\
(\geq 10)\end{array}$ & 32(20.3) & $21(22.6)$ & $11(16.9)$ & \\
\hline $\begin{array}{l}\text { Total score (mean } \pm \\
\text { SD) }\end{array}$ & $6.75 \pm 3.97$ & $7.12 \pm 4.10$ & $6.23 \pm 3.75$ & 0.168 \\
\hline Sleep quality & $1.08 \pm 0.78$ & $1.19 \pm 0.81$ & $0.91 \pm 0.70$ & 0.023 \\
\hline Sleep latency & $1.32 \pm 1.01$ & $1.37 \pm 1.00$ & $1.25 \pm 1.02$ & 0.481 \\
\hline Sleep duration & $0.66 \pm 0.83$ & $0.70 \pm 0.87$ & $0.62 \pm 0.76$ & 0.533 \\
\hline Sleep efficiency & $0.76 \pm 0.96$ & $0.81 \pm 0.98$ & $0.70 \pm 0.94$ & 0.510 \\
\hline Sleep disturbances & $1.27 \pm 0.85$ & $1.32 \pm 0.92$ & $1.20 \pm 0.74$ & 0.421 \\
\hline Sleep medication & $0.11 \pm 0.54$ & $0.10 \pm 0.53$ & $0.12 \pm 0.55$ & 0.763 \\
\hline Daytime dysfunction & $1.58 \pm 1.17$ & $1.66 \pm 1.26$ & $1.48 \pm 1.03$ & 0.347 \\
\hline
\end{tabular}

epilepsy suffered equally from sleep problems. In contrast, the frequency of seizures was the most important indicator that independently related to anxiety in women with epilepsy in this study. Anxiety and depression are always correlated with seizure frequency, both before and after treatment, and depressive symptoms and seizure frequency influence mutually, indicated by both cross-sectional and longitudinal studies $(28,29)$. Our data are consistent with this finding in terms of anxiety but not depression. The analysis showed that anxiety symptoms associated seizure frequency stronger in women than in men in this study. This phenomenon may result from women's higher level of psychological burden when facing a higher frequency of seizures, compared with male patients. Therefore, seizure-related factors impact the anxious status of women much more in comparison with men. For female PWE, good control of epilepsy and maintaining a positive and optimistic attitude toward seizures may help to reduce anxiety.

Predictors of depressive symptoms in PWE also varied by gender. It was notable in this study that depression was independently associated with education years and QOL social function in men with epilepsy but not in women. As reported, epilepsy often leads to poorer educational and vocational outcomes including unemployment and limited career prospects, especially for male patients (30). Data in the present study indicated that longer education years and better social function meant a lower risk of depression; on the contrary, poorly educated male PWE may have more psychological barriers and less-flexible coping strategies. In general, social support means differently to men and women. Women commonly relied on searching for social and religious support,
TABLE 4 | Correlation analysis of factors influencing mood of patients with epilepsy.

\begin{tabular}{|c|c|c|c|c|}
\hline \multirow[t]{2}{*}{ Variables } & \multicolumn{2}{|c|}{ Anxiety (SAS) } & \multicolumn{2}{|c|}{ Depression (SDS) } \\
\hline & $\begin{array}{c}\text { Men } \\
(\mathrm{N}=93)\end{array}$ & $\begin{array}{c}\text { Women } \\
(\mathrm{N}=65)\end{array}$ & $\begin{array}{c}\text { Men } \\
(\mathrm{N}=93)\end{array}$ & $\begin{array}{c}\text { Women } \\
(\mathrm{N}=65)\end{array}$ \\
\hline \multicolumn{5}{|l|}{ Demographic characteristics } \\
\hline Age & -0.007 & 0.156 & -0.073 & 0.152 \\
\hline Occupation & 0.102 & $-0.394^{\star \star}$ & 0.125 & $-0.400^{\star \star}$ \\
\hline Education years & -0.153 & $-0.422^{\star \star}$ & $-0.292^{\star \star}$ & $-0.416^{\star \star}$ \\
\hline Settlement & -0.027 & $-0.330^{\star \star}$ & 0.004 & $-0.360^{\star \star}$ \\
\hline \multicolumn{5}{|l|}{ Clinical characteristics } \\
\hline Onset age & -0.088 & 0.010 & -0.081 & -0.033 \\
\hline Duration & 0.175 & 0.081 & 0.026 & 0.111 \\
\hline Numberof AEDs & 0.151 & -0.075 & 0.090 & 0.064 \\
\hline Frequency of seizures & $0.207^{\star}$ & $0.467^{\star \star}$ & $0.230^{\star}$ & $0.377^{\star \star}$ \\
\hline Type of epilepsy & 0.072 & $-0.248^{*}$ & 0.096 & -0.205 \\
\hline \multicolumn{5}{|l|}{ QOLIE-31 } \\
\hline Total score & $-0.522^{* *}$ & $-0.606^{\star *}$ & $-0.564^{\star \star}$ & $-0.557^{\star *}$ \\
\hline Seizure worry & $-0.248^{*}$ & $-0.579^{\star \star}$ & $-0.303^{\star \star}$ & $-0.544^{\star *}$ \\
\hline Overall quality of life & $-0.371^{\star \star}$ & $-0.251^{*}$ & $-0.429^{\star \star}$ & $-0.262^{\star}$ \\
\hline Emotional well-being & $-0.521^{\star \star}$ & $-0.576^{\star \star}$ & $-0.511^{\star *}$ & $-0.642^{\star \star}$ \\
\hline Energy/fatigue & $-0.654^{\star \star}$ & $-0.697^{\star \star}$ & $-0.675^{\star \star}$ & $-0.676^{\star \star}$ \\
\hline Cognitive function & $-0.432^{\star \star}$ & $-0.392^{\star \star}$ & $-0.423^{\star \star}$ & $-0.363^{\star \star}$ \\
\hline Medication effects & $-0.225^{\star}$ & $-0.338^{\star *}$ & -0.181 & $-0.260^{\star}$ \\
\hline Social function & $-0.306^{\star \star}$ & $-0.416^{\star \star}$ & $-0.441^{\star \star}$ & $-0.348^{\star \star}$ \\
\hline \multicolumn{5}{|l|}{ PSQI } \\
\hline Total score & $0.467^{\star \star}$ & $0.445^{\star \star}$ & $0.388^{\star \star}$ & $0.330^{\star \star}$ \\
\hline Sleep quality & $0.318^{\star *}$ & $0.277^{\star}$ & $0.263^{\star}$ & $0.287^{\star}$ \\
\hline Sleep latency & $0.362^{\star \star}$ & $0.370^{\star \star}$ & $0.280^{\star \star}$ & $0.324^{\star \star}$ \\
\hline Sleep duration & 0.145 & 0.109 & 0.113 & 0.015 \\
\hline Sleep efficiency & 0.117 & 0.182 & 0.079 & 0.162 \\
\hline Sleep disturbances & $0.468^{\star \star}$ & $0.342^{\star \star}$ & $0.348^{\star *}$ & $0.291^{*}$ \\
\hline Sleep medication & $0.252^{\star}$ & $0.275^{\star}$ & $0.230^{\star}$ & 0.227 \\
\hline Daytime dysfunction & $0.402^{\star \star}$ & $0.483^{\star \star}$ & $0.344^{\star \star}$ & $0.306^{\star}$ \\
\hline
\end{tabular}

${ }^{*} p<0.05$.

${ }^{* *} p<0.01$.

while most men showed alexithymia and more difficulties on coping negative emotions (31), which may explain the gender differences in the predictors of depression in PWE in our study.

Our findings also suggest the importance of the relationship between fatigue and mental comorbidity in people with epilepsy. QOL medication effects, as the most important indicators of depression in both genders (32), were significant in our regression model of men with epilepsy. In women with epilepsy, rather than sociodemographic factors, QOL energy/ fatigue almost exclusively account for the variance in depression. The degree of fatigue was found higher in adult PWE than in the general population $(4,33)$. In this study, the bidirectional relationship between negative emotions and epilepsy was well established: QOL energy/fatigue was confirmed as the common predictor of comorbid anxiety and depression in both genders with epilepsy. Moreover, the male patients were influenced by QOL energy/fatigue to a greater extent than the female patients. Although the mechanism of fatigue remains unclear, previous studies have found that fatigue was prominent in people with major depressive disorder even when depression was atypical (34). Thus, the association between depression (or anxiety) and fatigue should be fully understood, and fatigue should 
TABLE 5 | Logistics analysis for anxiety in men or women with epilepsy.

\begin{tabular}{lccccc}
\hline & B & S.E. & Wald & OR & $\boldsymbol{p}$ \\
\hline Men & & & & & \\
Duration & 0.101 & 0.058 & 3.095 & 1.106 & 0.079 \\
Energy/fatigue (QOLIE-31) & -0.839 & 0.217 & 14.991 & 0.432 & $<0.001$ \\
PSQI & 0.292 & 0.107 & 7.491 & 1.339 & 0.006 \\
Women & & & & & \\
Frequency of seizures & 1.099 & 0.517 & 4.517 & 3.001 & 0.034 \\
Seizure worry (QOLIE-31) & -0.873 & 0.586 & 2.217 & 0.418 & 0.137 \\
Energy/fatigue (QOLIE-31) & -1.891 & 0.728 & 6.751 & 0.151 & 0.009 \\
\hline
\end{tabular}

TABLE 6 | Logistics analysis for depression in men or women with epilepsy.

\begin{tabular}{lccccc}
\hline & B & S.E. & Wald & OR & $\boldsymbol{p}$ \\
\hline Men & & & & & \\
Education years & -0.263 & 0.119 & 4.873 & 0.769 & 0.027 \\
Energy/fatigue (QOLIE-31) & -0.729 & 0.194 & 14.163 & 0.482 & 0.000 \\
Medication effects (QOLIE-31) & 0.907 & 0.498 & 3.314 & 2.477 & 0.069 \\
Social function (QOLIE-31) & -0.360 & 0.124 & 8.426 & 0.698 & 0.004 \\
PSQI & 0.163 & 0.097 & 2.863 & 1.177 & 0.091 \\
Women & & & & & \\
Seizure worry (QOLIE-31) & -0.621 & 0.348 & 3.186 & 0.537 & 0.074 \\
Energy/fatigue (QOLIE-31) & -1.328 & 0.398 & 11.108 & 0.265 & 0.001 \\
Medication effects (QOLIE-31) & 1.762 & 0.757 & 5.417 & 5.826 & 0.202 \\
MoCA & -0.201 & 0.104 & 3.736 & 0.818 & 0.053 \\
\hline
\end{tabular}

particularly be ameliorated in epilepsy patients. Seizure frequency and sleep-related problems have been found crucial risk factors for fatigue in epilepsy patients $(33,35)$, which may help to explain why PWE with anxiety disorders share fatigue as a common risk factor without gender differences.

In clinical practice, the main reason for psychiatric disorders in PWE usually is orchestration of large number of factors. However, our findings uncovered some interesting correlations between those factors, most of which serving as predictors for depression seem regulatable. Our study suggests that male and female PWE should be treated differently, particularly regard to negative emotional comorbidities. Further social support for male PWE and effective health education on epilepsy for female PWE may increase their confidence in treatment and relieve their anxiety about seizures.

\section{Limitations}

The following limitations should be considered when our data are being interpreted. (1) The cases were acquired from a single epilepsy center, and the sample size was relatively small. Thus the conclusion from these data cannot be applied to other patient groups directly. (2) A definitive diagnosis of depression or anxiety disorders should meet the Diagnostic and Statistical Manual of Mental Disorders (DSM) criteria by a comprehensive clinical examination. The SAS and SDS are brief screening instruments to assess the severity of anxiety or depressive symptoms and more appropriate for epidemiological research. (3) The data in our study were collected by participants' self-reports with no confirmation by professional psychiatric staff. Therefore, the patients may have over-evaluated or underreported their actual situation of epilepsy. (4) The main type of epilepsy in most PWE of our sample is generalized epilepsy, while focal epilepsy has a higher prevalence in the adults.

\section{CONCLUSION}

The data of this study suggest that there may be no gender difference in the prevalence of epilepsy comorbidity of anxiety and depression, but gender discrepancy plays a significant role in the incidence of psychiatric comorbidities in epilepsy. Most of the important predictors for anxiety and depression in PWE vary between genders: male patients are more likely to be affected by psychosocial factors, while female patients are more influenced by seizure-related events. In addition, common indicators (e.g., energy/fatigue) may influence the psychiatric comorbidities of epilepsy differently in male and female PWE. To improve the psychiatric condition and QOL of PWE, psychological interventions and related medical care should be tailored according to gender-specific predictors.

\section{DATA AVAILABILITY STATEMENT}

The raw data supporting the conclusions of this article will be made available by the authors, without undue reservation.

\section{ETHICS STATEMENT}

The studies involving human participants were reviewed and approved by The Ethics Committee of the 940th Hospital of Joint Logistics Support force of committee: Chinese People's Liberation Army (Department of Neurology, The 940th Hospital of Joint Logistics Support Force of People's Liberation Army, Lanzhou, Gansu, China.). The patients/participants provided their written informed consent to participate in this study.

\section{AUTHOR CONTRIBUTIONS}

SW and FK conceived of and designed the study. ZL, RY, ZF, HF, $\mathrm{HW}$, and BS were involved in data acquisition. ZL and FK analyzed the data and wrote the manuscript. All authors contributed to the article and approved the submitted version.

\section{FUNDING}

This work was funded by grants to SW (Innovation Teams in Priority Areas Accredited by the Ministry of Science and Technology, No. 2014RA4029) and ZL (Scientific Research Project of health industry in Gansu Province, No. GSWSKY2019-64).

\section{ACKNOWLEDGMENTS}

We would like to express our sincere appreciation to the included people with epilepsy and their families. 


\section{REFERENCES}

1. LaFrance WCJr., Kanner AM, Hermann B. Psychiatric comorbidities in epilepsy. Int Rev Neurobiol (2008) 83:347-83. doi: 10.1016/S0074-7742(08)00020-2

2. Lopez MR, Schachter SC, Kanner AM. Psychiatric comorbidities go unrecognized in patients with epilepsy: "You see what you know". Epilepsy Behav (2019) 98:302-5. doi: 10.1016/j.yebeh.2019.01.027

3. Scott AJ, Sharpe L, Hunt C, Gandy M. Anxiety and depressive disorders in people with epilepsy: A meta-analysis. Epilepsia (2017) 58:973-82. doi: 10.1111/epi.13769

4. Tellez-Zenteno JF, Matijevic S, Wiebe S. Somatic comorbidity of epilepsy in the general population in Canada. Epilepsia (2005) 46:1955-62. doi: 10.1111/ j.1528-1167.2005.00344.x

5. Tellez-Zenteno JF, Patten SB, Jette N, Williams J, Wiebe S. Psychiatric comorbidity in epilepsy: a population-based analysis. Epilepsia (2007) 48:2336-44. doi: 10.1111/j.1528-1167.2007.01222.x

6. Hesdorffer DC, Ishihara L, Mynepalli L, Webb DJ, Weil J, Hauser WA. Epilepsy, suicidality, and psychiatric disorders: a bidirectional association. Ann Neurol (2012) 72:184-91. doi: 10.1002/ana.23601

7. Kanner AM. Depression and epilepsy: A bidirectional relation? Epilepsia (2011) 52(Suppl 1):21-7. doi: 10.1111/j.1528-1167.2010.02907.x

8. Kanner AM. Management of psychiatric and neurological comorbidities in epilepsy. Nat Rev Neurol (2016) 12:106-16. doi: 10.1038/ nrneurol.2015.243

9. Altemus M, Sarvaiya N, Neill Epperson C. Sex differences in anxiety and depression clinical perspectives. Front Neuroendocrinol (2014) 35:320-30. doi: 10.1016/j.yfrne.2014.05.004

10. McLean CP, Asnaani A, Litz BT, Hofmann SG. Gender differences in anxiety disorders: prevalence, course of illness, comorbidity and burden of illness. J Psychiatr Res (2011) 45:1027-35. doi: 10.1016/j.jpsychires.2011.03.006

11. Mazza M, Martini A, Scoppetta M, Mazza S. Effect of levetiracetam on depression and anxiety in adult epileptic patients. Prog Neuropsychopharmacol Biol Psychiatry (2008) 32:539-43. doi: 10.1016/j.pnpbp.2007.10.015

12. Huang H, Che C, Liu C, Jiang F, Mao X. Factors associated with generic and disease-specific quality of life in epilepsy. BioMed Environ Sci (2011) 24:22833. doi: 10.3967/0895-3988.2011.03.001

13. Chen YY, Huang S, Wu WY, Liu CR, Yang XY, Zhao HT, et al. Associated and predictive factors of quality of life in patients with temporal lobe epilepsy. Epilepsy Behav (2018) 86:85-90. doi: 10.1016/j.yebeh.2018.06.025

14. Zhao Y, Ding C, Wang Y, Li Z, Zhou Y, Huang Y. Reliability and validity of a Chinese version of the Quality of Life in Epilepsy Inventory (QOLIE-89). Epilepsy Behav (2007) 11:53-9. doi: 10.1016/j.yebeh.2007.03.013

15. Cramer JA, Perrine K, Devinsky O, Bryant-Comstock L, Meador K, Hermann B. Development and cross-cultural translations of a 31-item quality of life in epilepsy inventory. Epilepsia (1998) 39:81-8. doi: 10.1111/j.1528-1157.1998. tb01278.x

16. Guekht AB, Mitrokhina TV, Lebedeva AV, Dzugaeva FK, Milchakova LE, Lokshina $\mathrm{OB}$, et al. Factors influencing on quality of life in people with epilepsy. Seizure (2007) 16:128-33. doi: 10.1016/j.seizure.2006.10.011

17. Saadi A, Patenaude B, Mateen FJ. Quality of life in epilepsy-31 inventory (QOLIE-31) scores: A global comparison. Epilepsy Behav (2016) 65:13-7. doi: 10.1016/j.yebeh.2016.09.032

18. Devinsky O, Vickrey BG, Cramer J, Perrine K, Hermann B, Meador K, et al. Development of the quality of life in epilepsy inventory. Epilepsia (1995) 36:1089-104. doi: 10.1111/j.1528-1157.1995.tb00467.x

19. Buysse DJ, Reynolds CF,3, Monk TH, Berman SR, Kupfer DJ. The Pittsburgh Sleep Quality Index: a new instrument for psychiatric practice and research. Psychiatry Res (1989) 28:193-213. doi: 10.1016/0165-1781(89)90047-4
20. Zheng W, Luo XN, Li HY, Ke XY, Dai Q, Zhang CJ, et al. Gender differences in the prevalence and clinical correlates of sleep disturbance in general hospital outpatients. Psychiatry Res (2018) 269:134-9. doi: 10.1016/j.psychres.2018.08.043

21. Breeman S, Cotton S, Fielding S, Jones GT. Normative data for the Hospital Anxiety and Depression Scale. Qual Life Res (2015) 24:391-8. doi: 10.1007/ s11136-014-0763-z

22. Gaus V, Kiep H, Holtkamp M, Burkert S, Kendel F. Gender differences in depression, but not in anxiety in people with epilepsy. Seizure (2015) 32:3742. doi: 10.1016/j.seizure.2015.07.012

23. Martin A, Rief W, Klaiberg A, Braehler E. Validity of the Brief Patient Health Questionnaire Mood Scale (PHQ-9) in the general population. Gen Hosp Psychiatry (2006) 28:71-7. doi: 10.1016/j.genhosppsych.2005.07.003

24. Latreille V, St Louis EK, Pavlova M. Co-morbid sleep disorders and epilepsy: A narrative review and case examples. Epilepsy Res (2018) 145:185-97. doi: 10.1016/j.eplepsyres.2018.07.005

25. Staner L. Sleep and anxiety disorders. Dialog Clin Neurosci (2003) 5:249-58. doi: 10.1016/j.psc.2006.08.005

26. Sutton EL. Psychiatric disorders and sleep issues. Med Clin North Am (2014) 98:1123-43. doi: 10.1016/j.mcna.2014.06.009

27. Kaur H, Bollu PC. Chronic Insomnia. Treasure Island (FL): StatPearls (2019).

28. Dehn LB, Pfafflin M, Bruckner S, Lutz MT, Steinhoff BJ, Mayer T, et al. Relationships of depression and anxiety symptoms with seizure frequency: Results from a multicenter follow-up study. Seizure (2017) 53:103-9. doi: 10.1016/j.seizure.2017.11.008

29. Thapar A, Roland M, Harold G. Do depression symptoms predict seizure frequency-or vice versa? J Psychosom Res (2005) 59:269-74. doi: 10.1016/ j.jpsychores.2005.04.001

30. de Barros ACS, Furlan AER, Marques LHN, de Araujo Filho GM. Gender differences in prevalence of psychiatric disorders, levels of alexithymia, and coping strategies in patients with refractory mesial temporal epilepsy and comorbid psychogenic nonepileptic seizures. Epilepsy Behav (2018) 82:1-5. doi: 10.1016/j.yebeh.2018.02.026

31. Burkert S, Kendel F, Kiep H, Holtkamp M, Gaus V. Gender differences in social support in persons with epilepsy. Epilepsy Behav (2015) 46:205-8. doi: 10.1016/j.yebeh.2015.02.041

32. Gilliam FG, Santos J, Vahle V, Carter J, Brown K, Hecimovic H. Depression in epilepsy: ignoring clinical expression of neuronal network dysfunction? Epilepsia (2004) 45(Suppl 2):28-33. doi: 10.1111/j.0013-9580.2004.452005.x

33. Kwon OY, Ahn HS, Kim HJ. Fatigue in epilepsy: A systematic review and meta-analysis. Seizure (2017) 45:151-9. doi: 10.1016/j.seizure.2016.11.006

34. Arnold LM. Understanding fatigue in major depressive disorder and other medical disorders. Psychosomatics (2008) 49:185-90. doi: 10.1176/ appi.psy.49.3.185

35. Kwon OY, Park SP. Interictal fatigue and its predictors in epilepsy patients: A case-control study. Seizure (2016) 34:48-53. doi: 10.1016/j.seizure.2015.12.003

Conflict of Interest: The authors declare that the research was conducted in the absence of any commercial or financial relationships that could be construed as a potential conflict of interest.

Copyright (c) 2020 Liu, Yin, Fan, Fan, Wu, Shen, Wu and Kuang. This is an openaccess article distributed under the terms of the Creative Commons Attribution License (CC BY). The use, distribution or reproduction in other forums is permitted, provided the original author(s) and the copyright owner(s) are credited and that the original publication in this journal is cited, in accordance with accepted academic practice. No use, distribution or reproduction is permitted which does not comply with these terms. 